\title{
Conservation area networks for the Indian region: Systematic methods and future prospects
}

\author{
Sahotra Sarkar*1, Michael Mayfield ${ }^{2}$, Susan Cameron ${ }^{3}$, Trevon Fuller ${ }^{1}$ and Justin Garson ${ }^{4}$ \\ ${ }^{1}$ Biodiversity and Biocultural Conservation Laboratory, Section of Integrative Biology, \\ University of Texas at Austin, 1 University Station C0930, Austin, Texas, USA 78712 \\ ${ }^{2}$ Wello Horld, Inc., 195 Morgan Avenue, Brooklyn, New York, USA 11237 \\ ${ }^{3}$ Graduate Group in Ecology, Department of Environmental Science and Policy, \\ University of California at Davis, Davis, California, USA 95616 \\ ${ }^{4}$ Department of Philosophy, University of Texas at Austin, 1 University Station C3500, Austin, Texas, USA 78712 \\ * For correspondence, email: sarkar@mail.utexas.edu
}

\begin{abstract}
We present a framework for systematic conservation planning for biodiversity with an emphasis on the Indian context. We illustrate the use of this framework by analyzing two data sets consisting of environmental and physical features that serve as surrogates for biodiversity. The aim was to select networks of potential conservation areas (such as reserves and national parks) which include representative fractions of these environmental features or surrogates. The first data set includes the entire subcontinent while the second is limited to the Eastern Himalayas. The environmental surrogates used for the two analyses result in the selection of conservation area networks with different properties. Tentative results indicate that these surrogates are successful in selecting most areas known from fieldwork to have high biodiversity content such as the broadleaf and subalpine conifer forests of the Eastern Himalayas. However, the place-prioritization algorithm also selected areas not known to be high in biodiversity content such as the coast of the Arabian Sea. Areas selected to satisfy a $10 \%$ target of representation for the complete surrogate set provide representation for $46.03 \%$ of the ecoregions in the entire study area. The algorithm selected a disproportionately small number of cells in the Western Ghats, a hotspot of vascular plant endemism. At the same target level, restricted surrogate sets represent $33.33 \%$ of the ecoregions in the entire study area and $46.67 \%$ of the ecoregions in the Eastern Himalayas. Finally, any more sophisticated use of such systematic methods will require the assembly of Geographical Information Systems (GIS)-based biogeographical data sets on a regional scale.
\end{abstract}

Key words: Indian biodiversity, Eastern Himalayas, complementarity, area prioritization, reserve selection, surrogacy

The Indian subcontinent is a region of moderate to very high biodiversity including two of the global hotspots of vascular plant endemism: the Western Ghats and the Eastern Himalayas (Myers et al. 2000). It has also had a long cultural history of biological conservation, going back almost 2,500 years in recorded history. Since independence in 1947, and particularly since 1970 , India has been one of the international leaders in setting aside land for biodiversity conservation. In spite of strong local interest, a highly developed scientific infrastructure, and considerable political will for conservation, systematic conservation planning methods from contemporary conservation biology have rarely been used in any Indian context (see, however, Pawar et al. 2007). Our purpose here is to provide a brief introduction to these neglected methods with particular attention to the Indian context, and then apply them to two Indian data sets. However, the data sets we use were generated from publicly available coarse-grained data from the World Wide Web. The only geographical data that are thus available for India are for environmental, that is, climatic and topographical, features. No geographical distributional data for biota were available. Consequently, we could only test the adequacy of using environmental features by assessing what fraction of each ecoregion was selected when we prioritized places for conservation using these features. However, the surrogates that we used effectively represent components of biodiversity in other regions (Sarkar et al. 2005, Margules and Sarkar 2007). Because of these limitations, our results indicate what conservation planning might achieve if the ongoing Indian and transnational ecoinformatics projects compile adequate data in appropriate form. They should not guide policy formulation. In the future, we hope to repeat this analysis with more adequate data sets, and to provide

Himalayan Journal of Sciences 4(6): 27-40, 2007

Available online at www.himjsci.com

Copyright@2007 by Himalayan Association for the

Advancement of Science 


\section{Box 1. Glossary of technical terms}

Conservation area: Any geographical unit at which a conservation plan for biodiversity is being implemented. There is no restriction on what such a plan may be.

Conservation area network: A network of conservation areas which are jointly intended to satisfy representation targets for biodiversity and other goals. The main goal of systematic conservation planning is to identify such networks.

\section{Estimator surrogate: See surrogate.}

Goal: A desired spatial configuration of conservation areas in a conservation area network, for instance, with specified sizes or shapes of individual areas, their dispersion across the study region, or the connectivity between them. Also refers to desired social, political, and economic consequences of a conservation area network.

Representation level: A quantitative measure of the extent to which a biodiversity surrogate is present in a conservation area network, for instance, the fraction of the habitat of some species.

Surrogate: Biological or environmental (climatic or topographic) features that are used to measure biodiversity in conservation planning. Biological features may be sets of species or other taxa as well as community types. True surrogates are those such features used to capture biodiversity generally. Estimator surrogates are used to represent true surrogates when the geographical distributions of true surrogates cannot be accurately measured.

True surrogate: See surrogate.

Target: A required level of representation for each surrogate in an adequate conservation area network.

policy recommendations. Nonetheless, for one case in peninsular India our results do suggest the need for a new program of investigative research. (For an explanation of the terminology used in this paper, see Box 1.)

The following section of this paper describes a systematic conservation planning and management framework previously used by conservation planners in many countries, including Australia, Canada, Papua New Guinea, and South Africa. (For details, see Margules and Sarkar 2007; for a historical review, see Justus and Sarkar 2002.) We tailored the discussion to the Indian context. In the "Materials and methods" section, we describe the data sets, algorithms, and software tools we use. In the "Results" section, we provide our initial findings and analyze their implications in "Discussion" section.

\section{Systematic biodiversity conservation planning and management}

The aim of biodiversity conservation planning is to select conservation area networks (CANs) and to devise methods for their adequate management. We define a conservation area as an area in which some conservation action is implemented. Such actions include the designation of traditional reserves with human exclusion, but they also include sustainable human use and management. (This is why we prefer the term "conservation area" to the more traditional "reserve.") Box 2 details the framework for systematic conservation planning and management as an eleven-stage process which is described in detail by Margules and Sarkar (2007; see also Margules and Pressey 2000). The first stage is the identification of stakeholders for a given region and discussion of process and general goals. The next stage is data collection. It is critical that the data be georeferenced and recorded in a Geographical Information System (GIS) model. As part of this stage, planners must identify the biological entities that are of the most interest for conservation. These obviously include species that are at risk and also those that are endemic or rare. Planners must also assess the quality of the data. Even though no techniques exist as yet to quantify uncertainties in the data, and how these propagate through the analysis, the best possible assessment of the quality of the data must nevertheless guide the interpretation of results. The last point will be illustrated as we discuss our own results.

The third stage of conservation planning is the selection of surrogates to represent general biodiversity. In this context, there is an operationally useful distinction between "true" and "estimator" surrogates for biodiversity (Sarkar and Margules 2002, Margules and Sarkar 2007). The former must represent biodiversity in general. However, since general biodiversity has so far proved impossible to define, we must use some convention. Though there are many plausible alternatives, the most common convention has been to regard the set of all species as a true surrogate set (Sarkar 2002). Unfortunately, complete distributions of such comprehensive true surrogate sets are almost always impossible to obtain in practice: consequently, conservation planners have to use estimator surrogates. Whereas true surrogates have general biodiversity as their target of representation, estimator surrogates have true surrogates as their target. Estimator surrogates must be landscape features that are easily and accurately quantified and assessed. These surrogates may be sets of species or higher taxa, as well as environmental parameters such as climatic variables and land classes. Whether an estimator surrogate set adequately represents an explicitly specified true surrogate set is a question that conservation planners must evaluate empirically in the field. Planners can evaluate the extent to which an estimator surrogate set represents a true surrogate set in two ways: (i) planners can use the estimator surrogate distributions to predict the true surrogate distributions, for instance, through niche modeling; or (ii) planners can compare results of planning using estimator surrogates to those obtained using the true surrogates. So far planners have never successfully implemented method (i) for large complements of biota at the landscape scale. However, planners have used method (ii) with some success (Ferrier and Watson 1997, Garson et al. 2002a, Sarkar et al. 2006). Typically, planners must survey a small, suitably randomized set of sites for both the true and potential estimator surrogates. Planners must then prioritize 
Box 2. Systematic conservation action

1. Identify stakeholders for the planning region:

- Stakeholders include: (a) those who have decisionmaking powers; (b) those who will be affected by conservation plans for region; (c) those with expertise about the region and (d) those who may commit resources for conservation plans;

- Include both local and global stakeholders;

- Ensure transparency in the involvement of all stakeholders from the beginning.

2. Compile, assess, and refine biodiversity and socioeconomic data for the region:

- Compile available geographical distribution data on as many biotic and environmental parameters as possible at every level of organization;

- Compile available socio-economic data, including values for alternate uses, resource ownership and infrastructure;

- Collect relevant new data to the extent feasible within available time; remote sensing data should be easily accessible; systematic surveys at the level of species (or lower levels) will usually be impossible;

- Assess conservation status for biotic entities, for instance, their rarity, endemism, and endangerment;

- Assess the reliability of the data, formally and informally; in particular, critically analyze the process of data selection;

- When data do not reflect representative samples of the landscape, correct for bias and model distributions.

\section{Select biodiversity surrogates for the region:}

- Choose true surrogate sets for biodiversity (representing general "biodiversity") for part of the region; be explicit about criteria used for this choice;

- Choose alternate estimator surrogate sets (for representing true surrogate sets in the planning process);

- Prioritize sites using true surrogate sets; prioritize sites using as many combinations of estimator surrogate sets as feasible, and compare them;

- Potentially also use other methods of surrogacy analysis to assess estimator-surrogate sets, including measures of spatial congruence between plans formulated using the true and estimator surrogate sets;

- Assess which estimator surrogate set is best on the basis of (i) economy and (ii) representation.

4. Establish conservation targets and goals:

- Set quantitative targets for surrogate coverage;

- Set quantitative targets for total network area;

- Set quantitative targets for minimum size for population, unit area, etc.;

- Set design criteria such as shape, size, dispersion, connectivity, alignment, and replication;

- Set precise goals for criteria other than biodiversity, including socio-political criteria.

5. Review the existing conservation area network (CAN):

- Estimate the extent to which the existing set of conser-vation areas meets the conservation targets and goals;
- Determine the prognosis for the existing CAN;

- Refine the first estimate.

6. Prioritize new areas for potential conservation action:

- Using principles such as complementarity, rarity, and endemism, prioritize areas for their biodiversity content to create a set of potential conservation area networks;

- Starting with the existing CAN, repeat the process of prioritization to compare results;

- Incorporate socio-political criteria, such as various costs, if desired, using a trade-off analysis;

- Incorporate design criteria such as shape, size, dispersion, connectivity, alignment, and replication, if desired, using a trade-off analysis.

- Alternatively, carry out last three steps using optimal algorithms.

\section{Assess prognosis for biodiversity within each newly} selected area:

- Assess the likelihood of persistence of all biodiversity surrogates in all selected areas. This may include population viability analysis for as many species using as many models as feasible;

- Perform the best feasible habitat-based viability analysis to obtain a general assessment of the prognosis for all species in a potential conservation area;

- Assess vulnerability of a potential conservation area from external threats, using techniques such as risk analysis.

8. Refine networks of areas selected for conservation action:

- Delete the presence of surrogates from potential conservation areas if the viability of that surrogate is not sufficiently high;

- Run the prioritization protocol again to prioritize potential conservation areas by biodiversity value;

- Incorporate design criteria such as shape, size, dispersion, connectivity, alignment, and replication.

9. Examine feasibility using multi-criteria analysis:

- Order each set of potential conservation areas by each of the criteria other than those used in Stage 6;

- Find all best solutions; discard all other solutions;

- Select one of the best solutions.

\section{Implement a conservation plan:}

- Decide on most appropriate legal mode of protection for each targeted place;

- Decide on most appropriate mode of management for persistence of each targeted surrogate;

- If implementation is impossible return to Stage 5;

- Decide on a time frame for implementation, depending on available resources.

11. Periodically reassess the network:

- Set management goals in an appropriate time-frame for each protected area;

- Decide on indicators that will show whether goals are met;

- Periodically measure these indicators;

- Return to Stage 1. 
areas using both true and estimator surrogate sets (see the discussion of the sixth stage below) and compare the results. The subset of potential estimator surrogates that achieves the closest level of representation of the true surrogate set is the best to use for the entire region for which the full distributions of true surrogates are not known.

At the fourth stage, conservation planners must establish explicit targets and goals for the conservation area network. Here, targets refer to the quantitative level of representation of surrogates in conservation area networks (see below). Goals refer to both the spatial configuration of networks (the size, shape, dispersion, connectivity, etc. of the areas in the network) as well as social and economic aspects. Without explicit targets and goals, it is impossible to assess the success of a conservation plan. However, setting such targets and goals provides ample scope for controversy. Typically, planners use two types of targets: (i) a level of representation for each surrogate within a conservation area network (CAN); or (ii) the area of land that can be put under a conservation plan. A common target of type (i) is to set the level of representation at $100 \%$ for species at risk and $10 \%$ for all other surrogates. A common target of type (ii) is $10 \%$ of the total area of a region, as originally proposed by the World Wide Fund for Nature (WWF) and the International Union for the Conservation of Nature and Natural Resources (IUCN) (Dudley et al. 1996). However, the actual numbers used are not entirely determined by biological criteria. Rather, they represent conventions arrived at by educated intuition. Similarly, while planners generally accept on ecological grounds that larger conservation areas are better than smaller

Table 1. Representation of ecoregions among selected cells for the Indian region

\begin{tabular}{|c|c|c|c|c|}
\hline Ecoregion & $\begin{array}{l}\text { All } \\
\text { Surrogates } \\
\mathbf{5 \%}\end{array}$ & $\begin{array}{l}\text { All } \\
\text { Surrogates } \\
10 \%\end{array}$ & $\begin{array}{l}\text { Restricted } \\
\text { Surrogates } \\
\mathbf{5 \%}\end{array}$ & $\begin{array}{l}\text { Restricted } \\
\text { Surrogates } \\
10 \%\end{array}$ \\
\hline Andaman Islands rain forests & 0.00 & 42.88 & 0.00 & 0.00 \\
\hline Baluchistan xeric woodlands & 4.26 & 14.11 & 0.04 & 7.76 \\
\hline Brahmaputra Valley semi-evergreen forests & 0.39 & 0.78 & 0.00 & 0.20 \\
\hline Central Afghan Mountains xeric woodlands & 6.04 & 15.71 & 0.03 & 10.11 \\
\hline Central Deccan Plateau dry deciduous forests & 4.70 & 7.45 & 0.05 & 6.06 \\
\hline Central Tibetan Plateau alpine steppe & 1.42 & 3.37 & 0.02 & 2.84 \\
\hline Chhota-Nagpur dry deciduous forests & 9.10 & 11.21 & 0.07 & 8.83 \\
\hline Chin Hills-Arakan Yoma montane forests & 12.20 & 28.65 & 0.13 & 23.68 \\
\hline Deccan thorn scrub forests & 4.62 & 6.36 & 0.02 & 11.54 \\
\hline East Afghan montane conifer forests & 0.00 & 0.00 & 0.00 & 7.47 \\
\hline East Deccan dry-evergreen forests & 0.00 & 0.00 & 0.00 & 0.00 \\
\hline Eastern highlands moist deciduous forests & 4.71 & 12.13 & 0.04 & 10.38 \\
\hline Eastern Himalayan alpine shrub and meadows & 6.68 & 9.79 & 0.07 & 10.26 \\
\hline Eastern Himalayan broadleaf forests & 14.77 & 26.69 & 0.10 & 28.66 \\
\hline Eastern Himalayan subalpine conifer forests & 24.64 & 28.34 & 0.30 & 37.78 \\
\hline Goadavari-Krishna mangroves & 0.00 & 1.92 & 0.02 & 1.92 \\
\hline Himalayan subtropical broadleaf forests & 6.12 & 26.78 & 0.01 & 3.20 \\
\hline Himalayan subtropical pine forests & 7.37 & 15.28 & 0.05 & 10.20 \\
\hline Hindu Kush alpine meadow & 0.00 & 7.74 & 0.02 & 14.04 \\
\hline Indus River Delta-Arabian Sea mangroves & 13.76 & 19.88 & 0.00 & 25.85 \\
\hline Indus Valley desert & 0.00 & 0.00 & 0.00 & 0.00 \\
\hline Karakoram-West Tibetan Plateau alpine steppe & 4.00 & 14.19 & 0.05 & 6.60 \\
\hline Khathiar-Gir dry deciduous forests & 2.57 & 5.59 & 0.03 & 10.55 \\
\hline Kuh Rud and Eastern Iran montane woodlands & 0.42 & 10.02 & 0.00 & 0.42 \\
\hline Lower Gangetic Plains moist deciduous forests & 3.50 & 5.98 & 0.04 & 6.27 \\
\hline Malabar Coast moist forests & 1.32 & 2.33 & 0.00 & 0.98 \\
\hline Meghalaya subtropical forests & 7.18 & 17.02 & 0.05 & 11.42 \\
\hline Mizoram-Manipur-Kachin rain forests & 4.41 & 11.72 & 0.01 & 2.08 \\
\hline Myanamar Coast mangroves & 0.00 & 0.00 & 0.00 & 0.00 \\
\hline
\end{tabular}


ones, ecology does not specify how large is good enough. The question of connectivity also remains controversial: while connectivity might help species migrate to find suitable habitat, it may also enable the spread of infectious disease.

At the fifth stage, planners must assess the performance of existing conservation areas in meeting the targets and goals of the fourth. This will determine what conservation action (if any) they should take. Because conservation practitioners have never implemented systematic conservation planning in India, it is unknown whether, and to what extent, the existing network of protected areas adequately represents India's biodiversity. It is only in the southern region (Kerala, southern Karnataka, and Tamil Nadu) that close to $10 \%$ of the land is under some form of protection. However, we do not know whether the existing areas are spatially economical, that is, selected so as to represent biodiversity maximally in the area of land that has been put under protection.

The sixth stage consists of prioritizing places for conservation action to satisfy the stated targets and goals of the fourth stage. The result is a potential CAN. This problem corresponds to the traditional problem of reserve network selection. We purposely chose the term "place prioritization" rather than the more traditional "reserve selection" in order to emphasize that systematic conservation planning envisions a variety of conservation actions, including, but not limited to, the designation of reserves. A wide variety of algorithms and other methods are available for place prioritization (Cabeza and Moilanen 2001). The algorithm used here will be discussed in "Materials and methods" section. It is designed to construct a CAN as economically

\begin{tabular}{|c|c|c|c|c|}
\hline Myanmar coastal rain forests & 5.07 & 22.79 & 0.04 & 8.76 \\
\hline Narmada Valley dry deciduous forests & 3.39 & 8.15 & 0.04 & 8.38 \\
\hline Nicobar Islands rain forests & 10.01 & 0.00 & 0.00 & 0.00 \\
\hline North Tibetan Plateau-Kunlun Mountains alpine desert & 3.69 & 7.40 & 0.03 & 7.39 \\
\hline North Western Ghats moist deciduous forests & 5.86 & 15.09 & 0.03 & 7.83 \\
\hline North Western Ghats montane rain forests & 14.09 & 22.59 & 0.06 & 16.78 \\
\hline Northeast India-Myanmar pine forests & 1.15 & 3.47 & 0.00 & 2.31 \\
\hline Northeastern Himalayan subalpine conifer forests & 2.34 & 5.83 & 0.02 & 6.05 \\
\hline Northern dry deciduous forests & 0.20 & 2.76 & 0.00 & 0.60 \\
\hline Northern Triangle temperate forests & 0.00 & 0.00 & 0.03 & 4.04 \\
\hline Northwestern Himalayan alpine shrub and meadows & 9.15 & 18.19 & 0.07 & 17.55 \\
\hline Northwestern thorn scrub forests & 3.70 & 5.83 & 0.01 & 5.76 \\
\hline Orissa semi-evergreen forests & 3.17 & 16.89 & 0.00 & 4.22 \\
\hline Pamir alpine desert and tundra & 3.34 & 4.86 & 0.03 & 4.52 \\
\hline Rann of Kutch seasonal salt marsh & 4.51 & 16.45 & 0.07 & 7.39 \\
\hline Registan-North Pakistan sandy desert & 4.93 & 11.13 & 0.06 & 10.67 \\
\hline Rock and ice & 11.69 & 23.74 & 0.12 & 23.42 \\
\hline South Deccan Plateau dry deciduous forests & 0.00 & 5.44 & 0.00 & 5.87 \\
\hline South Iran Nubo-Sindian desert and semi-desert & 21.16 & 32.18 & 0.24 & 35.02 \\
\hline South Western Ghats moist deciduous forests & 3.08 & 7.19 & 0.07 & 1.03 \\
\hline South Western Ghats montane rain forests & 11.04 & 24.19 & 0.09 & 4.22 \\
\hline Sri Lanka dry-zone dry evergreen forests & 0.00 & 3.30 & 0.00 & 0.00 \\
\hline Sri Lanka lowland rain forests & 0.00 & 9.81 & 0.03 & 0.00 \\
\hline Sri Lanka montane rain forests & 4.17 & 12.50 & 0.21 & 12.50 \\
\hline Sulaiman Range alpine meadows & 0.00 & 2.58 & 0.00 & 1.74 \\
\hline Sundarbans freshwater swamp forests & 0.00 & 0.00 & 0.00 & 0.00 \\
\hline Sundarbans mangroves & 0.00 & 0.00 & 0.00 & 4.22 \\
\hline Terai-Duar savanna and grasslands & 0.00 & 5.77 & 0.03 & 6.14 \\
\hline Thar desert & 4.25 & 6.85 & 0.03 & 5.50 \\
\hline Upper Gangetic Plains moist deciduous forests & 1.57 & 1.86 & 0.00 & 0.67 \\
\hline Western Himalayan alpine shrub and meadows & 11.93 & 22.04 & 0.08 & 22.34 \\
\hline Western Himalayan broadleaf forests & 14.85 & 21.54 & 0.16 & 25.00 \\
\hline Western Himalayan subalpine conifer forests & 12.56 & 18.22 & 0.13 & 23.03 \\
\hline
\end{tabular}


Table 2. Representation of ecoregions among selected cells for the Eastern Himalayas

\begin{tabular}{|c|c|c|}
\hline Ecoregion & $\begin{array}{l}\text { Restricted } \\
\text { surrogates } \\
\mathbf{5 \%}\end{array}$ & $\begin{array}{l}\text { Restricted } \\
\text { surrogates } \\
10 \%\end{array}$ \\
\hline $\begin{array}{l}\text { Brahmaputra Valley semi- } \\
\text { evergreen forests }\end{array}$ & 1.49 & 10.82 \\
\hline $\begin{array}{l}\text { Chin Hills-Arakan Yoma } \\
\text { montane forests }\end{array}$ & 4.20 & 4.59 \\
\hline $\begin{array}{l}\text { Eastern Himalayan alpine } \\
\text { shrub and meadows }\end{array}$ & 5.00 & 11.02 \\
\hline $\begin{array}{l}\text { Eastern Himalayan } \\
\text { broadleaf forests }\end{array}$ & 6.59 & 15.55 \\
\hline $\begin{array}{l}\text { Eastern Himalayan } \\
\text { subalpine conifer forests }\end{array}$ & 4.70 & 6.67 \\
\hline $\begin{array}{l}\text { Himalayan subtropical } \\
\text { broadleaf forests }\end{array}$ & 8.45 & 48.99 \\
\hline $\begin{array}{l}\text { Himalayan subtropical pine } \\
\text { forests }\end{array}$ & 4.50 & 4.69 \\
\hline $\begin{array}{l}\text { Lower Gangetic Plains } \\
\text { moist deciduous forests }\end{array}$ & 0.90 & 70.25 \\
\hline $\begin{array}{l}\text { Meghalaya subtropical } \\
\text { forests }\end{array}$ & 5.53 & 10.19 \\
\hline $\begin{array}{l}\text { Mizoram-Manipur-Kachin } \\
\text { rain forests }\end{array}$ & 3.81 & 5.40 \\
\hline $\begin{array}{l}\text { Northeast India-Myanmar } \\
\text { pine forests }\end{array}$ & 5.74 & 6.74 \\
\hline $\begin{array}{l}\text { Northeastern Himalayan } \\
\text { subalpine conifer forests }\end{array}$ & 4.84 & 7.51 \\
\hline $\begin{array}{l}\text { Northern Triangle } \\
\text { temperate forests }\end{array}$ & 3.41 & 8.65 \\
\hline Rock and ice & 2.50 & 3.66 \\
\hline $\begin{array}{l}\text { Terai-Duar savanna and } \\
\text { grasslands }\end{array}$ & 6.42 & 13.30 \\
\hline
\end{tabular}

as possible, that is with the least number of areas put under management for biodiversity conservation.

However, the current representation of biodiversity in a CAN does not solely ensure its persistence: conservation planners must also take into account the level of threat from ecological and anthropogenic factors. The seventh stage of systematic conservation planning consists of assessing such risks (Gaston et al. 2002). This is often a difficult task, and planners have paid relatively little attention to it. Techniques for coping with risk include population and habitat-based viability analysis, as well as threat estimation (Boyce 1992, Boyce et al. 1994). Planners have not carried out any of these for any Indian region.

In the eighth stage, conservation planners drop areas with a poor prognosis for relevant biodiversity features and repeat the place prioritization excluding these areas. Biodiversity conservation is not the only possible use of land. Competing uses such as agriculture, recreation, or industrial development, place strong socio-economic constraints on environmental policy. The ninth stage consists of attempting to synchronize all these criteria. Many interesting conceptual and practical problems arise at this stage, the main one being whether we can compound all these criteria in one utility function to be maximized (Janssen 1992, Faith 1995, Sarkar and Garson 2003, Moffett and Sarkar 2006). Systematic conservation planning in India has never reached this stage.

The end of the ninth stage produces a plan for implementation. An attempt at implementation constitutes the tenth stage of the conservation process. If implementation is impossible, as it sometimes is because of the constraints encountered, new plans must be formulated. This requires a return to the sixth stage. Finally, conservation action is not a one-time process. The status of biological entities changes over time. Consequently, the last stage consists of repeating the entire process after a period of time. Conservation planners may set this period of time in absolute terms (a specified number of years, once again chosen by convention) or planners may determine the period by keeping track of explicitly specified indicators of the health of a conservation area network. The conservation planning literature sometimes refers to this iterative process as adaptive management.

\section{Materials and methods}

Data sets Our starting point is the map of terrestrial ecoregions of the world produced by the WWF (http:// www.worldwildlife.org/ecoregions/, Olson et al. 2001). In Figure 1, we overlaid all of the ecoregions that partly or fully overlap the political map of India to produce the region of analysis. The first part of our analysis encompasses the entirety of this region which we will refer to as the "Indian region." We divided this region into cells at a resolution of $0.1^{\circ} \times 0.1^{\circ}$ of longitude and latitude, resulting in 63,954 cells which varied in size from 94.6 to $123.6 \mathrm{sq}$. km. (The variation in area is due to the fact that the distance between lines of longitude decreases away from the equator.) The region of analysis has a total area of 6,987,279.29 sq. km and represents 63 ecoregions.

As estimator surrogates we used climatic parameters (annual mean temperature, the minimum temperature during the coldest period, the maximum temperature during the hottest period, and precipitation), slope, elevation, aspect, and soil classes. Since we had no access to biogeographical distributional data, we judged the adequacy of our surrogate set on the basis of its ability to select representative fractions of the ecoregions. (Olson et al. [2001] defined the ecoregions based in part on coarse-grained biological features.) However, we have previously shown this estimator surrogate set to be adequate in representing biota for two widely different data sets from Queensland and Québec (Sarkar et al. 2005).

We obtained elevation data from the GTOPO30 DEM which is a 30 arc-second DEM available from the United States Geological Survey (USGS) (USGS 1998, http:// edcdaac.usgs.gov/gtopo30/gtopo30.html). We created slope and aspect layers using the Spatial Analyst extension in ArcGIS 8.1 (ESRI 2002) from the DEM as specified in the Hydro $1 \mathrm{~K}$ elevation derivative database methodology 


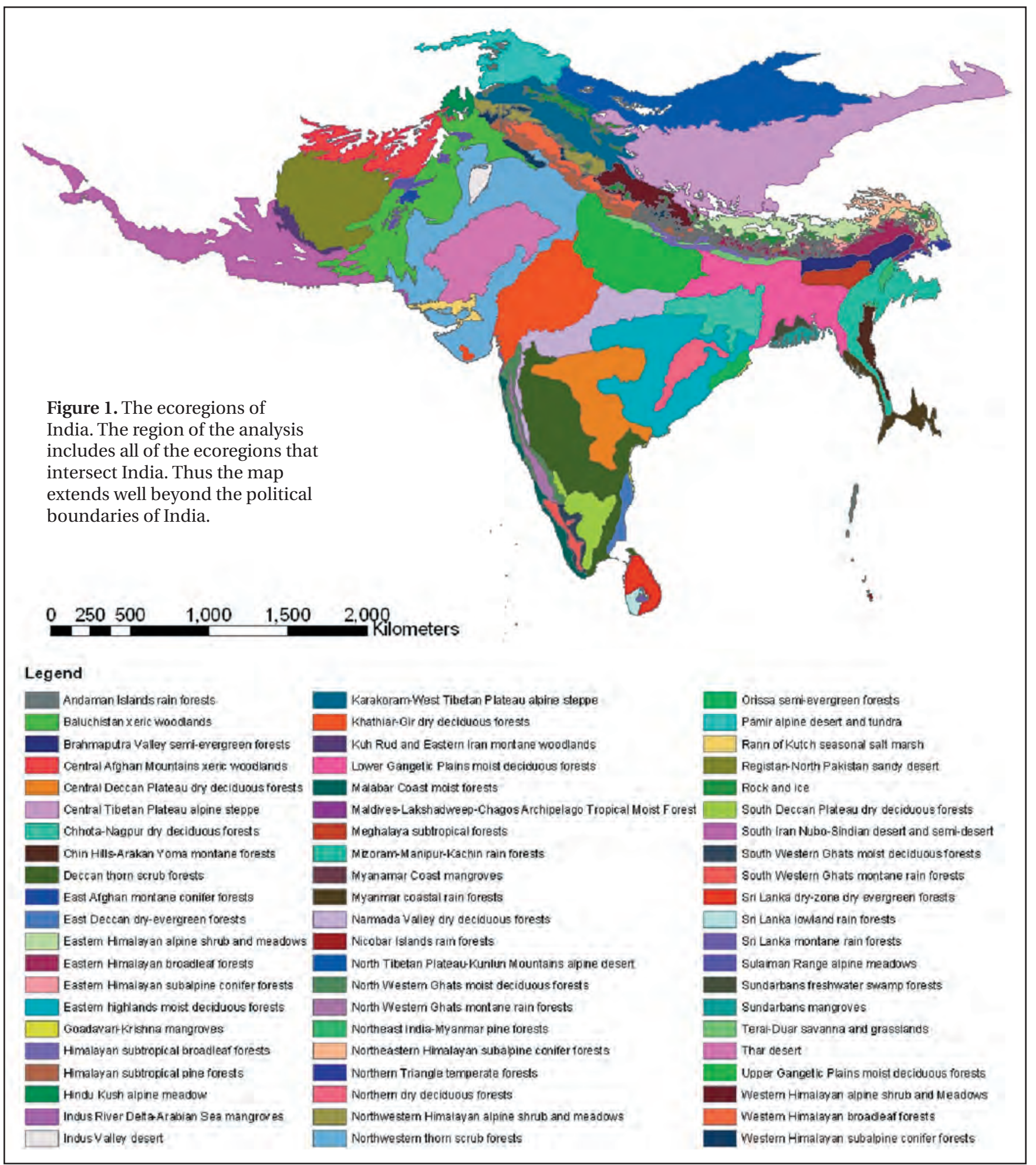

(http://edcdaac.usgs.gov/gtopo30/hydro/index.html) also available from USGS.

We created the annual precipitation, mean temperature, minimum temperature of the coldest period, and maximum temperature of the coldest period layers from the GTOPO30 DEM and the FAOCLIM worldwide agroclimatic database (FAO 2000, http://www.fao.org/sd/2001/EN1102_en.htm) using the ANUSPLIN 4.1 (Hutchinson 2000, http:// cres.anu.edu.au/outputs/anusplin.html) and ANUCLIM 5.1 (Houlder et al. 2000, http://cres.anu.edu/outputs/ anuclim.html) software packages available from the Centre for Resource and Environmental Studies at the Australian National University. We used procedures for running ANUSPLIN and ANUCLIM identical to those used in the 
Australian BioRap analysis (Hutchinson 1991, Hutchinson et al. 1996). In ANUSPLIN, we used the same default values as in BioRap analysis for the SELNOT and SplineB programs.

We obtained soil classifications for India from the world soil resources map (http://www.fao.org/sd/eidirect/ gis/chap7.htm) created by the Food and Agriculture Organization of the United Nations (FAO 1993). There were only 13 associations of soil types, making this the most coarse-grained (and least satisfactory) of our estimator surrogate sets.

We divided the annual mean temperature data (range: $-19^{\circ}$ to $29^{\circ} \mathrm{C}$ ) and annual precipitation data (range: 15 to $7,873 \mathrm{~mm}$ ) into 10 equal interval classes. We divided the minimum temperature of the coldest period of the year (range: $-40^{\circ}$ to $24^{\circ} \mathrm{C}$ ) and the maximum temperature of the warmest period of the year (range: $0^{\circ}$ to $45^{\circ} \mathrm{C}$ ) into four equal interval classes. We did not attach any significance to the exact number of classes: these choices reflect the intuition that mean temperature matters more for biodiversity than the annual high and low temperatures. However, there is an important reason why we used equal intervals: this attempts to ensure that a conservation plan adequately represents biotic features found in rare temperature regimes (for instance, species found in hot desert and cold tundra environments).

We divided slope into five classes based on standard deviations (range: $0^{\circ}$ to $52^{\circ}$ below the horizon). The use of standard deviations reflects an assumption that mid-range slopes are more important for biodiversity than extremes. We based this assumption on the fact that the two biodiversity hotspot regions in the Indian region (the Western Ghats and the Eastern Himalayas) are in mountains that have most of their biota in the mid-range of slope. However, this assumption may introduce an unjustified bias against the plains, which are also important for Indian biodiversity. To guard against this bias, we divided elevation (1 to $8752 \mathrm{~m}$ ) into 25 classes based on quantiles. The use of quantiles gives preference to flatter regions. We divided the soil data into 13 classes based on the 13 soil association types that occur within the region (FAO 1993). We divided aspect into eight classes based on the cardinal directions (N, NE, E, SE, S, SW, W, NW).

Thus, there were a total of 79 estimator surrogates. We also repeated our analysis without using slope, aspect, and elevation since these were used to calculate the climatic parameters. There were then a total of 41 estimator surrogates in the repeated analysis.

For our second data set, we partitioned the Eastern Himalayas at the finer scale of $0.01^{\circ} \times 0.01^{\circ}$ of longitude and latitude to obtain some preliminary indicative results because we plan to do further work on this region. We overlaid the 15 ecoregions that intersected with the Eastern Himalayas and then eliminated non-mountainous terrain using an elevation threshold of $400 \mathrm{~m}$. There were 365,347 cells which varied in area between 1.06 and $1.18 \mathrm{sq}$. km. The total area of the region was $401,834.03$ sq. $\mathrm{km}$.

In the Eastern Himalayas, there are 15 ecoregions. We only used the truncated estimator surrogate set in order to keep the computations tractable. We divided the annual mean temperature data (range: $-19^{\circ}$ to $25^{\circ} \mathrm{C}$ ) and annual precipitation data (395 to $7873 \mathrm{~mm}$ ) into 10 equal interval classes. We divided the minimum temperature of the coldest period of the year $\left(-40^{\circ}\right.$ to $\left.14^{\circ} \mathrm{C}\right)$ and the maximum temperature of the warmest period of the year $\left(0^{\circ}\right.$ to $\left.36^{\circ} \mathrm{C}\right)$ into four equal interval classes. Soil data were divided into four classes, corresponding to the four soil association types that occur in the region. We did not include elevation, aspect, and slope data in this analysis. Thus, there were a total of 32 estimator surrogates.

Algorithms and software We performed all computations using the ResNet Ver. 1.2 software package initialized with rarity (Garson et al. 2002b). This software package implements a CAN selection algorithm fully described by Sarkar et al. (2002). We used targets of $5 \%$ and $10 \%$ of the total distribution of the surrogates. To initiate the construction of a CAN, we selected the first cell by the presence of the rarest surrogate in the data set. We then iteratively augmented the CAN by adding cells using rarity again and, if there were ties, by breaking them by complementarity. (The complementarity value of a cell is the number of surrogates in it that have not yet achieved their targets.) We broke remaining ties by a random selection of a cell. Finally, we removed redundant cells. It is well-established that such rarity-complementarity algorithms lead to very economical CANs, that is, those that achieve all the prescribed targets with as few cells as possible (Csuti et al. 1997, Pressey et al. 1997). Such economy is important because the addition of a unit to a CAN imposes costs, including the cost of acquisition and the cost of forgone opportunities (Sarkar et al. 2006).

\section{Results}

Figure 2a shows the selected cells for the entire Indian region when we used all 79 surrogates with a target of representation of $5 \%$; Figure $2 \mathbf{b}$ is the result when we set the target at $10 \%$. ResNet selected 3,223 cells with an area of 353,991.82 sq. km. or $5.07 \%$ of the total area in Figure 2a; 6,472 cells with an area of $688,047.22$ sq. km. or $10.32 \%$ of the total area in Figure $2 \mathbf{b}$. Table 1 shows the percentage of the area selected for each of the 63 ecoregions. These results permit some assessment of the adequacy of our estimator surrogates. When we used a target of 5\% representation of surrogates, only 20 out of 63 ecoregions have at least $5 \%$ of their area selected; at a $10 \%$ surrogate representation, 29 ecoregions achieve a $10 \%$ area representation. With very few exceptions, the areas selected at the $10 \%$ representation augment those selected at the $5 \%$ representation.

In Figures 3a, b, the result of using only 41 surrogates is superimposed on those of using all 79 surrogates for $5 \%$ and $10 \%$ targets for the Indian region. The observation that a very high percentage of cells was selected in the Himalayan region motivated this exercise. It is possible that the selection of these cells is an artifact of the fact that these mountain ranges have extremes of slope and elevation. Moreover, we used slope, aspect, and elevation in our calculation of the climatic layers. Thus these three parameters and the climatic parameters are not independent of each other and it is at least intuitively plausible - though it has never been 
Figure 2. Selected areas in the Indian region:

(a) target of representation of 5\%; (b) target of

representation of $10 \%$. The selected cells are

shown in dark blue.
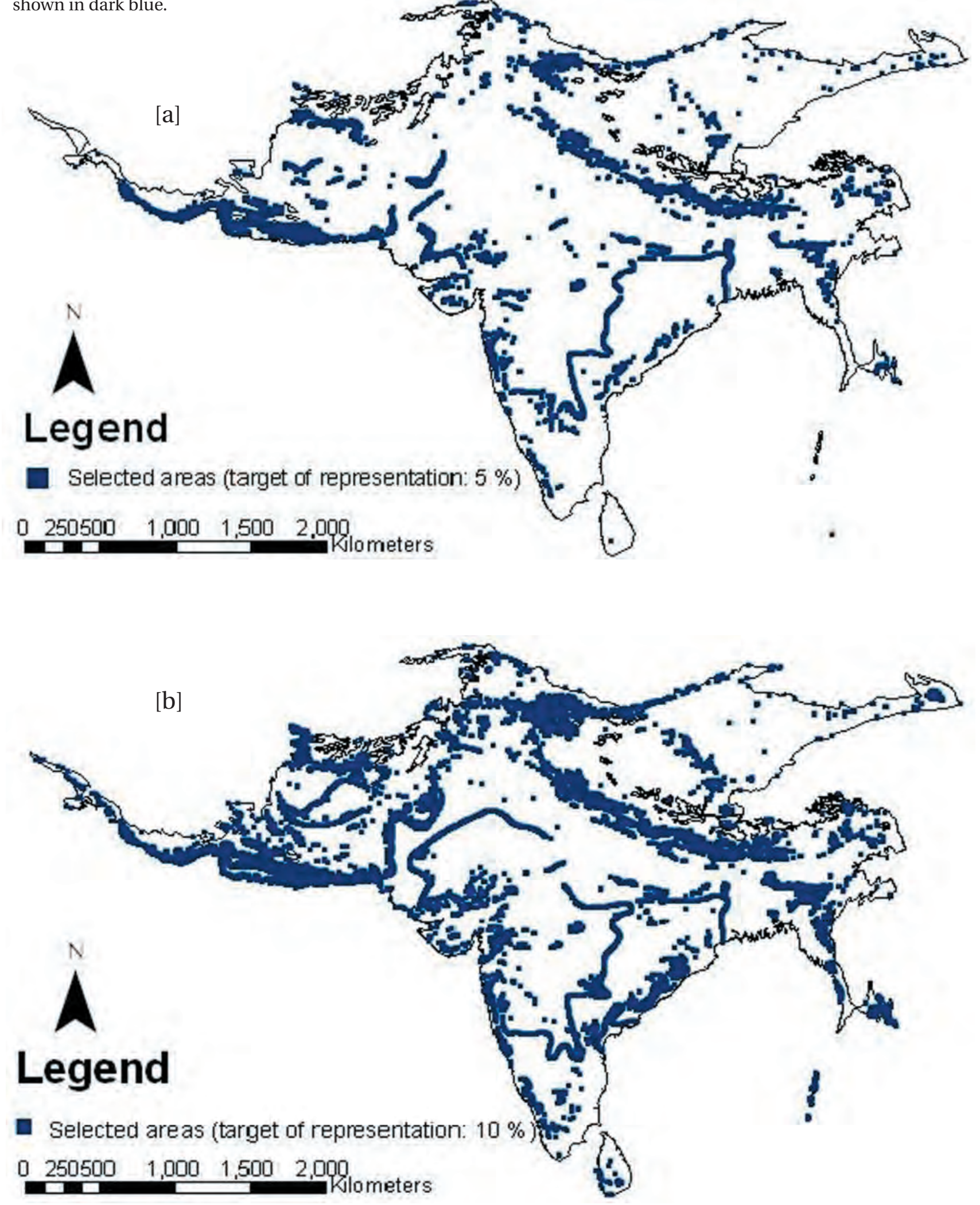
Figure 3. Effect of surrogate set composition on selected areas: (a) target of representation of 5\%; (b) target of representation of $10 \%$. When we used all 79 surrogates, the areas selected are shown in light blue. When we used only 41 surrogates (excluding slope, aspect, and elevation), the selected cells are super-imposed in dark blue. (The additional cells selected when there are 79 surrogates appear visible in light blue.)
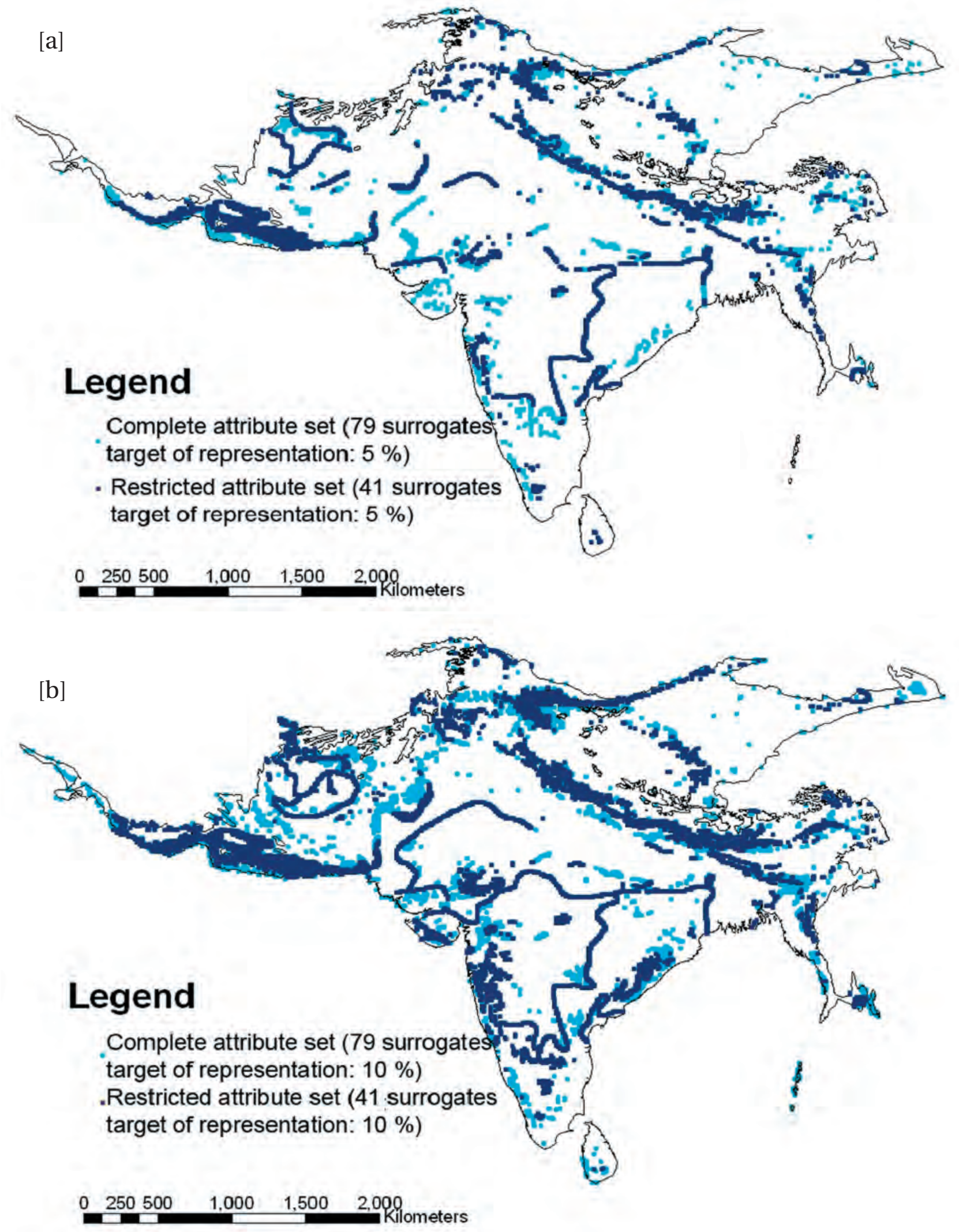
[a]
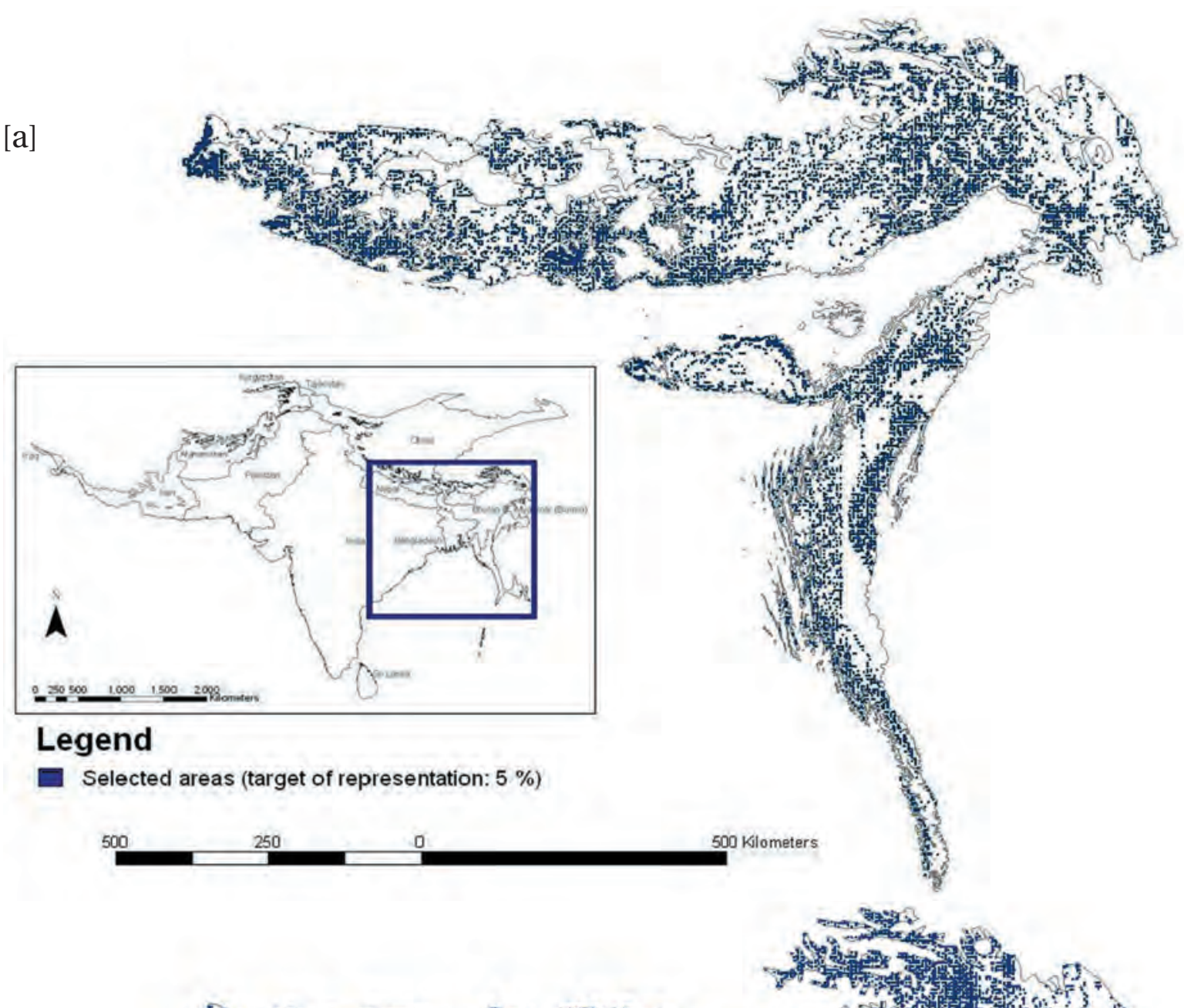

[b]
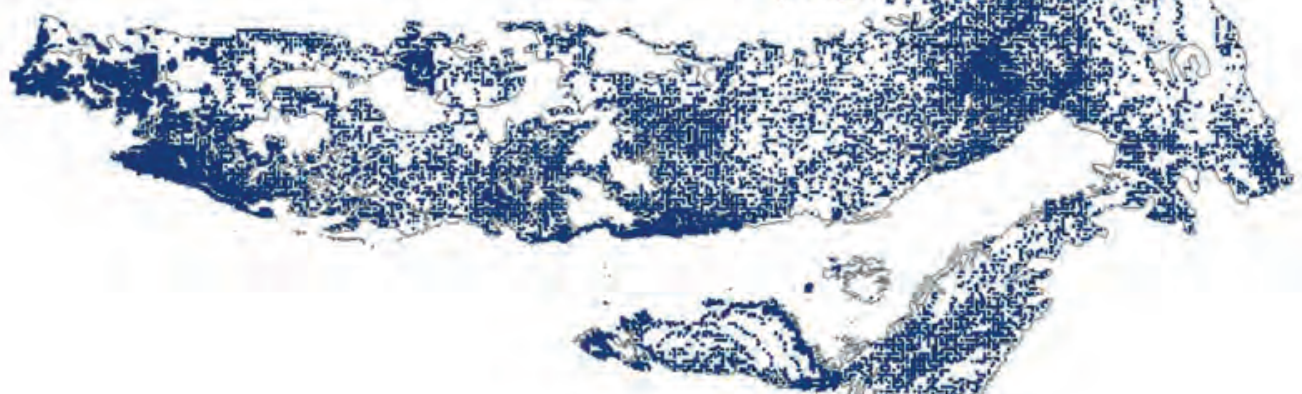

Figure 4. Selected areas in the Eastern Himalayas: (a) target of representation of 5\%; (b) target of representation of $10 \%$. The selected cells are shown in dark blue. Inset: Countries bordering the Eastern Himalayan ecoregion. The blue box in the inset shows the Eastern Himalayas.

\section{Legend}

Selected areas (target of representation: $10 \%$ )

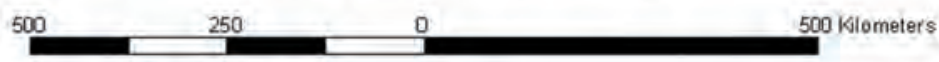


proved-that the best estimator surrogate sets are those that include only independent parameters. In this case, no ecoregion achieves 5\% area representation with 5\% surrogate representation. However, 21 ecoregions achieve a $10 \%$ area representation with a target of $10 \%$ surrogate representation. Thus, at least at the $5 \%$ level, we do not recommend using results obtained with the truncated surrogate set for policy development. However, the results shown in Figures 3a, b are not qualitatively different from those in Figures $2 \mathbf{a}, \mathbf{b}$ though, as expected, with fewer surrogates, ResNet selected less cells. In Figure 3a, ResNet selected 2816 cells with an area of $308,219.26$ sq. km. or $4.41 \%$ of the total area; in Figure 3b, 5,637 cells with an area of $618,275.36$ sq. $\mathrm{km}$. or $8.85 \%$ of the total area.

Figures 4 a shows the selected cells for the entire Eastern Himalayas at a $0.01^{\circ} \times 0.01^{\circ}$ longitude $\times$ latitude scale when we used 32 surrogates, ignoring slope, aspect, and elevation, with a target of representation of $5 \%$; Figure $4 \mathrm{~b}$ is the result when we set the target at $10 \%$. As noted before, we used the truncated set for computational efficiency. Below we will show that it does not perform as poorly for the Eastern Himalayas as it does for the entire Indian region. The fact that conservation planning in the Indian region takes place at the regional rather than the subcontinental level motivated this exercise. We investigated whether there is a significant loss of economy if targets of (local) representation must be met within the confines of each region. In Figure 4a, ResNet selected 17,985 cells with an area of $19,745.31$ sq. km. or $4.91 \%$ of the total area; in Figure $4 \mathrm{~b}, 35,945$ cells with an area of $39,386.67$ sq. $\mathrm{km}$. or $9.8 \%$ of the total area. Table 2 shows the shows the percentage of the area selected for each of the 15 ecoregions.

At both the $5 \%$ and the $10 \%$ surrogate representation level, seven out of the 15 ecoregions achieved the corresponding level of area representation (5\% or $10 \%)$. That the truncated surrogate set performs relatively well for the Eastern Himalayas is probably a result of their being fewer ecoregions present compared to the entire Indian region (15 versus 63). (It is unlikely that this difference in percentage is due to the change in the spatial scale of analysis. In general, surrogates perform better at larger spatial scales Garson et al. (2002a), and this effect is likely to be enhanced when there are fewer surrogates present.)

\section{Discussion}

With the increasing population and per capita resource use in India, the near future will see an increase in anthropogenic demands on habitats. Consequently, systematic conservation planning and management is a necessity, not a luxury. However, going beyond the preliminary and incomplete results of this analysis will require the availability of GISbased biogeographic data on as many taxa and habitat types as possible at regional or larger scales. Planners should regard the creation of such databases as one of the highest priorities for biodiversity conservation in India. This will require large-scale collaborative efforts between governmental and non-governmental institutions including those involved in education and environmental advocacy. These efforts must begin with an assessment of what data are available in computerized and non-computerized forms, and also of the data quality. This was the first stage of the framework presented in the section "Systematic biodiversity conservation planning and management". Collaborative biodiversity conservation programs would be beneficial in South Asia because participant countries could work together to solve funding, infrastructure, and training problems (Gupta et al. 2002). International collaborations of this sort have proven fruitful for mangrove conservation in South Asia (Clüsener-Godt 2002, WWF and ICIMOD 2001), bioprospecting for marine natural products (Berlinck et al. 2004), and research in medicinal botany supported by the International Cooperative Biodiversity Group (Lewis 2003). In addition, a larger proportion of the biodiversity content of the Indian region could be surveyed if several countries participate in the conservation planning process (WWF and ICIMOD 2001, CEPF 2005). Collaborative conservation programs will require the establishment of common standards for the representation of data, a problem that is yet to be fully solved anywhere. Until the creation of databases conservation planning in India can only be ad hoc, a procedure that is known to be uneconomical (Pressey 1994, Pressey and Cowling 2001). Such ad hoc CAN selection often leads to the inclusion of biologically irrelevant areas in CANs, and thus the illegitimate exclusion of human economic and other interests. For obvious political reasons, this is a situation that is best avoided.

With respect to the entire Indian region, the Himalayas are over-represented in our nominal CANs (Table 1, Figures 2a, b). This should come as no surprise because we used elevation, slope, and aspect along with climatic parameters derived using them. This region is known to have high biodiversity content. However the selection of a large number of cells in the coastal region along the Arabian Sea west of India may be entirely an artifact of the data set used. The variation in environmental parameters selected by our analysis does not correspond to known variation in biodiversity content. It is also surprising that ResNet selected relatively few cells in the Western Ghats. We conjecture that while environmental estimator surrogates may adequately capture biological diversity, they do not perform well at capturing endemism which is much more dependent on the biogeographic history of a place. Similarly, the representation of the Sunderbans and Nicobar Island rain forests is not adequate. In peninsular India, ResNet also selected cells along fronts simultaneously separating soil association types and climatic regimes. Planners have generally ignored these in conservation decisions in this region. Our results suggest that conservation practitioners should systematically investigate these areas for their biodiversity content: this is the only case where our results are more than merely illustrative and may have practical use.

For the Eastern Himalayas, the most interesting result is that the selected cells are fairly evenly distributed across most of the Eastern Himalayas. If this result continues to hold when a conservation plan uses demonstrably adequate surrogate sets, and across spatial scales, it will have an important implication for conservation planning for the Eastern Himalayas: conservation planning must pay 
attention to the entire region, and not only to a small set of large conservation areas. Our results are partially discordant with those obtained by Pawar et al. (2007) who found priority areas to be somewhat more concentrated towards the higher elevation regions of the landscape (rather than the low elevation Brahmaputra valley). However, that study used modeled amphibian and reptile distributions as surrogates and explicitly noted that planners should not interpret the results to identify priority areas for all biota.

Finally, we emphasize again that we intend the analysis presented here to be illustrative and not to guide policy. We have shown how decision-makers can draw many conclusions with implications for conservation planning even from limited data so long as those data are represented as a GIS model. However, for such an analysis to have even partial relevance for policy formulation, at the very least, the conservation plan must include accurate vegetation maps. If, as a first step, such maps were made available, then future studies could test the adequacy of the surrogates used here. Classification of remotely sensed data (that is, satellite imagery) can often provide such vegetation maps. However, our results do suggest that planners should systematically investigate the fronts separating soil association types and climatic regimes in peninsular India for their biodiversity features. We end with the suggestion that conservation practitioners make it an immediate priority to create GISbased vegetation maps for India's two recognized hotspots of vascular plant endemism, the Western Ghats and the Eastern Himalayas.

\section{Software availability}

Users can download the ResNet Ver. 1.2 software package for free from http://uts.cc.utexas.edu/ consbio/Cons/ Labframeset.html.

\section{Acknowledgements}

This work was supported by NSF Grant No. SES-0645884.

\section{References}

Berlinck RGS, E Hajdu, RM da Rocha, JHHL de Oliveira, ILC Hernandez, MHR Seleghim, AC Granato, EVR de Almeida, CV Nunez, G Muricy, S Peixinho, C Pessoa, MO Moraes, BC Cavalcanti, GGF Nascimento, O Thiemann, M Silva, AO Souza, CL Silva and PRR Minarini. 2004. Challenges and rewards of research in marine natural products chemistry in Brazil. Journal of Natural Products 67(3): 510-522

Boyce MS. 1992. Population viability analysis. Annual Review of Ecology and Systematics 23: 481-506

Boyce MS, JS Meyer and L Irwin. 1994. Habitat-based PVA for the Northern Spotted Owl. In: Fletcher DJ and BFJ Manly (eds), Statistics in ecology and environmental monitoring. Dunedin: University of Otago Press, p 63-85

Cabeza M and A Moilanen. 2001. Design of reserve networks and the persistence of biodiversity. Trends in Ecology and Evolution 16(5): 242-248

CEPF [Critical Ecosystem Partnership Fund] 2005. Ecosystem profile: Indo-Burman hotspot, Eastern Himalayan region. Washington: WWF US-Asian Program. $97 \mathrm{p}$

Clüsener-Godt M. 2002. Asia-Pacific cooperation for the sustainable use of renewable natural resources in Biosphere Reserves and similarly managed areas. Trees-Structure and Function 16(2-3): $230-234$
Csuti B, S Polasky, PH Williams, RL Pressey, JD Camm, M Kershaw, AR Kiester, B Downs, R Hamilton, M Huso and K Sahr. 1997. A comparison of reserve selection algorithms using data on terrestrial vertebrates in Oregon. Biological Conservation 80(1): 83-97

Dudley N, D Gilmour and J.-P. Jeanrenaud (eds). 1996. Forests for life: the WWF/ IUCN forest policy book. Gland: WWF and IUCN. $62 \mathrm{p}$

Environmental Systems Resource Institute (ESRI). 2002. ArcMap 8.1. Redlands, California: ESRI

Faith DP. 1995. Biodiversity and regional sustainability analysis. Lyneham: CSIRO Division of Wildlife and Ecology. $30 \mathrm{p}$

Ferrier S and G Watson. 1997. An evaluation of the effectiveness of environmental surrogates and modelling techniques in predicting the distribution of biological diversity. Arimidale: Environment Australia. Consultancy report to the Biodiversity Convention and strategy section of the Biodiversity Group, Environment Australia. $184 \mathrm{p}$

Food and Agriculture Organization of the United Nations (FAO). 1993. World soil resources: an explanatory note on the FAO World Soil Resources Map at 1: 25,000,000 scale. Rome: FAO. World soil resources report no. 66, rev. 1

Food and Agriculture Organization of the United Nations (FAO) Agrometeorology Group. 2000. FAOCLIM 2: a worldwide agroclimatic database. Rome: FAO. Environment and natural resources working paper no. 5 .

Garson J, A Aggarwal and S Sarkar. 2002a. Birds as surrogates for biodiversity: an analysis of a data set from southern Québec. Journal of Biosciences 27(S2): 347-360

Garson J, A Aggarwal, and S Sarkar. 2002b. ResNet ver 1.2 manual. Austin: University of Texas Biodiversity and Biocultural Conservation Laboratory. $44 \mathrm{p}$

Gaston KJ, RL Pressey and CR Margules. 2002. Persistence and vulnerability: retaining biodiversity in the landscape and in protected areas. Journal of Biosciences 27(S2): 361-384

Gupta BM, UM Munshi and PK Mishra. 2002. S\&T collaboration of India with other South Asian countries. Current Science 83(10): 1201-1209

Houlder D, M Hutchinson, H Nix and J McMahon. 2000. ANUCLIM user's guide, version 5.1. Canberra: Centre for Resource and Environmental Studies, Australian National University

Hutchinson MF. 1991. The application of thin plate smoothing splines to continent-wide data assimilation. In: JD Jasper (ed), Data assimilation systems. Melbourne: Bureau of Meteorology. Bureau of meteorology research report no. 27. p 104-113

Hutchinson MF. 2000. ANUSPLIN user's guide, version 4.1. Canberra: Centre for Resource and Environmental Studies, Australian National University

Hutchinson MF, L Belbin, AO Nicholls, HA Nix, JP McMahon and KD Ord. 1996. BioRap. Volume two. Spatial modeling tools. Canberra: The Australian BioRap Consortium. $142 \mathrm{p}$

Janssen R. 1992. Multiobjective decision support for environmental management. Dordrecht: Kluwer. $248 \mathrm{p}$

Justus J and S Sarkar. 2002. The principle of complementarity in the design of reserve networks to conserve biodiversity: a preliminary history. Journal of Biosciences 27(S2): 421-435

Lewis WH. 2003. Pharmaceutical discoveries based on ethnomedicinal plants: 1985 to 2000 and beyond. Economic Botany 57(1): 126-134

Margules CR and RL Pressey. 2000. Systematic conservation planning. Nature 405(6783): 242-253

Margules CR and S Sarkar. 2007. Systematic conservation planning. Cambridge, UK: Cambridge University Press. 270 p

Moffett A and S Sarkar. 2006. Incorporating multiple criteria into the design of conservation area networks: a mini-review with recommendations. Diversity and Distributions 12(2): 125-137

Myers N, RA Mittermeier, CG Mittermeier, GA da Fonseca and J Kent. 2000. Biodiversity hotspots for conservation priorities. Nature 403(6772): 853-858

Olson DM, E Dinerstein, ED Wikramanayake, ND Burgess, GVN Powell, EC Underwood, JA D'Amico, I Itoua, HE Strand, JC Morrison, CJ Loucks, TF Allnutt, TH Ricketts, Y Kura, JF 


\section{Research paper}

Lamoreux, WW Wettengel, P Hedao and KR Kassem. 2001. Terrestrial ecoregions of the world: a new map of life on Earth. BioScience 51(11): 933-938

Pawar S, MS Koo, C Kelley, MF Ahmed, S Chaudhuri and S Sarkar. 2007. Conservation assessment and prioritization of areas in Northeast India: priorities for amphibians and reptiles. Biological Conservation 136(3): 346-361

Pressey RL. 1994. Ad hoc reservations: forward of backward steps in developing representative reserve systems. Conservation Biology 8(3): 662-668

Pressey RL and RM Cowling. 2001. Reserve selection algorithms and the real world. Conservation Biology 15(1): 275-277

Pressey RL, HP Possingham and JR Day. 1997. Effectiveness of alternative heuristic algorithms for approximating minimum requirements for conservation reserves. Biological Conservation 80(2): 207-219

Sarkar S. 2002. Defining "biodiversity": assessing biodiversity. Monist 85(1): 131-155

Sarkar S, A Aggarwal, J Garson, CR Margules and J Zeidler. 2002. Place prioritization for biodiversity content. Journal of Biosciences
27(S2): 339-346

Sarkar S and J Garson. 2003. Multiple criterion synchronization (MCS) for conservation area network design: the use of non-dominated alternative sets. Conservation and Society 2(2): 433-448

Sarkar S, J Justus, T Fuller, C Kelley, J Garson and M Mayfield. 2005. Effectiveness of environmental surrogates for the selection of conservation area networks. Conservation Biology 19(3): 815-825

Sarkar S and CR Margules. 2002. Operationalizing biodiversity for conservation planning. Journal of Biosciences 27(S2): 299-308

Sarkar S, RL Pressey, DP Faith, CR Margules, T Fuller, DM Stoms, A Moffett, KA Wilson, KJ Williams, PH Williams and S Andelman. 2006. Biodiversity conservation planning tools: present status and challenges for the future. Annual Review of Environment and Resources 31: 123-159

United States Geological Survey. 1998. GTOPO30 Global 30 Arcsecond Digital Elevation Model. Sioux Falls, South Dakota, USA: Center for Earth Resources Observation and Science

WWF and ICIMOD. 2001. Ecoregion-based conservation in the Eastern Himalaya: identifying important areas for biodiversity conservation. Kathmandu: WWF Nepal. 178 p 